\title{
Herbert Jasper: an Appreciation and a Tribute on His 90th Birthday
}

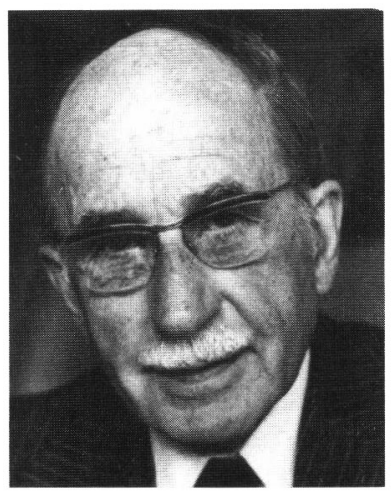

It is particularly fitting that at this reception of members of the Canadian Neurological and Clinical Neurophysiologists Societies at the American Academy of Neurology we should honour Dr. Herbert Jasper. He is, at the age of 90 , a living legend in the neurosciences. It is a rare opportunity for the young people who have followed him to meet a pioneer of his generation, let alone somebody who continues to this day to exercise his wise counsel and his extraordinary grasp of the working of the human brain.

Herbert Jasper, like Wilder Penfield, was born in the west of the United States, and, like his friend and colleague, became a Canadian and a founder of Canadian Neuroscience.

Jasper started his career as a psychologist of physiological persuasion and studied with Lapique who is remembered for his studies on chronaxie, in Paris. He became aware of Berger's writings on the electroencephalogram and realized early the enormous potential of being able to record the electrical activity generated by the human brain. In the $30 \mathrm{~s}$, two schools of epilepsy developed in North America: the medical with William Lennox in Boston, and the surgical with Wilder Penfield in Montreal.

Herbert Jasper was at that time working in the department of psychology at Brown University in Providence, Rhode Island. Wilder Penfield invited him to come and record the EEGs of some of his epileptic patients. Jasper would, after a week's work, load the EEG machine in the trunk of his car and proceed over the icy New England roads to Montreal. There he would study patients over the weekend and then return to Providence. Penfield then prevailed upon Jasper to move to the Montreal Neurological Institute (MNI) and thus began a period of extraordinary productivity, collaboration and friendship.

Since that time our perspective on epilepsy has been shaped by EEG and clinical neurophysiology. Jasper's Montreal school and the Boston group with Fred and Erna Gibs were friendly rivals in the race to unveil the mysteries of epilepsy. Jasper attracted a distinguished succession of brilliant young men from all parts of the world. He became the godfather of electroencephalography wherever epilepsy was being studied and he was the mentor of such outstanding clinical scientists as Henri Gastaut and Pierre Gloor and of more basic neurophysiologists such as David Ingvar, David Hubel and many more.

Electroencephalography allowed the localization studies which confirmed clinical observation and which led to the flowering of interest in the surgical treatment of focal epilepsies. It still remains the gold standard of localization in epilepsy and has been complemented more recently by the advent of modern imaging. Thus clinical observation, EEG, imaging and neuropsychology are the four pillars on which the recent explosion of interest in the field of surgical treatment of epilepsy rests.

In addition to their attempts to alleviate human suffering, Jasper and his colleagues were driven by the desire to under- stand brain function, his original reason to devote himself to neurophysiology.

The culmination of Jasper's and Penfield's work came with the publication of their landmark book, Epilepsy and the Functional Anatomy of the Human Brain in the mid 50s. This is when I met Herbert Jasper. I marvelled then and I still do, at his extraordinary capacity to summarize at meetings a whole day's presentations of complex physiological and clinical studies with clarity, simplicity, and above all with an enthusiasm which generated in all present the desire to return to the bedside or bench and to continue to pursue their research.

Jasper earned many honours in his long and productive life. He has become an honourary member of numberless professional societies touching on neurophysiology and neurology and an honourary Doctor of many universities. He is a founder and past President of the International Brain Research Organization, a life long supporter of the World Health Organization and he was one of the first to establish scientific contact with Russian neurophysiology in the 60 s. He then focussed on more basic neurophysiology at the Université de Montréal and contributed greatly to the development of the Center for Neurosciences at that university. He never lost interest in clinical epilepsy and his questions and comments to this day provide stimulation and encouragement for the younger generations to continue on the path of investigation.

Herbert Jasper was happily married to Ms. Goldie whom he met at the Montreal Neurological Institute and is a devoted father to his two children now working in the United Kingdom. He then married Marylou MacDougall with whom he has again found happiness. He has given up sailing, a sport he loved, and we are all familiar with the photograph of Dr. Penfield's boat, the Astrocyte, on which Herb Jasper was the crew. He also loved his summer home on Lake Memphre-magog where he shot himself in the spleen by accident trying to save his dog from the onslaught of a particularly aggressive groundhog.

I am particularly grateful to Dr. Jasper for the kindness and encouragement which he has shown both me and my wife, when, as neophytes we directed our interest to electroencephalography. The eyes of the new generation of epilepsy fellows at the MNI light up when they are introduced to Herbert Jasper. He continues to provide an example and an inspiration as he has done for over 60 years. It is, therefore, most fitting that the Canadian Society of Clinical Neurophysiologists and the Canadian Neurological Society, have decided to honour Herbert Jasper at this reception. For me, it has been a privilege to reminisce about those early days of the epilepsy movement in Canada and at the MNI in particular.

Frederick Andermann

Presented at Canada Night Reception at the American Academy of Neurology Meeting, San Francisco, March 28, 1996. 